Hospital Practice

\title{
Is bed rest useful after diagnostic lumbar puncture?
}

\author{
D.A. Spriggs, D.J. Burn, J. French, N.E.F. Cartlidge and D. Bates \\ Department of Neurology, Royal Victoria Infirmary, Queen Victoria Road, Newcastle upon Tyne NE1 \\ $4 L P, U K$
}

\begin{abstract}
Summary: A randomized study of 110 patients undergoing their first diagnostic lumbar puncture was performed to compare the effect of immediate mobilization with $\mathbf{4}$ hours bed rest on the incidence of post lumbar puncture headache. There was no difference between the mobile $(n=54)$ and bed rest $(n=56)$ groups in the incidence of post lumbar puncture headache (32\% versus $31 \%$, respectively). We conclude that bed rest following lumbar puncture may be an unnecessary imposition on the patient, as well as on nursing staff.
\end{abstract}

\section{Introduction}

Post lumbar puncture headache (PLPH) occurs in about $30 \%$ of patients undergoing diagnostic lumbar puncture (LP). ${ }^{1}$ Several investigators have examined the effect of posture assumed after $\mathrm{LP}^{2-4}$ but only one study ${ }^{5}$ has compared the effect of immediate immobilization with bed rest on the incidence of PLPH. Although this study can be criticized because patients were not randomly allocated, it showed no difference in the incidence of PLPH between 50 patients kept ambulant and 50 patients given 24 hours bed rest.

In 1986 , Gibb and Wen ${ }^{6}$ surveyed current practice for diagnostic LP and found that 24 out of 28 doctors recommended at least 2 hours bed rest in the hope of preventing PLPH. If bed rest was unnecessary, the administrative and nursing advantages would be obvious, especially in neurological units, where LPs are often done as day case procedures. We therefore examined the incidence PLPH in mobile and bed-rested patients.

\section{Material and methods}

One hundred and ten patients undergoing their first diagnostic LP on a neurology ward, who did not have a preceding headache, who could be mobilized after the LP and complete a written

Correspondence: D.J. Burn, M.R.C.P., MRC Cyclotron Unit, Hammersmith Hospital, Du Cane Road, London W12 0HS, UK.

Accepted: 24 February 1992 questionnaire, were recruited into the study. The ethical committee of the Newcastle Health Authority approved the study. All patients gave informed consent. They were told that the study was examining 'the effect of posture on the outcome of lumbar puncture'. Prior to the LP, randomized, consecutive numbers were allocated to each patient. Those receiving an even number were asked to lie supine in bed for 4 hours and were nursed in that position, while those receiving an odd number were advised to walk around at will. Table I summarizes the patient details and the reasons for undergoing LP for each group. Each patient was given a questionnaire, to be completed 7 days after the LP and posted back to the department. The doctor performing the LP filled in a proforma on completion of the LP. The number of red blood cells in the cerebrospinal fluid (CSF) was recorded as a measure of the degree of trauma due to the procedure. PLPH was defined as any headache lasting more than 2 hours in duration, that was moderate or severe in intensity, helped by lying down and dissimilar to any previously experienced headache.

Statistical analysis was on an intention to treat basis. One patient was incorrectly allocated to the supine group and was therefore analysed in that group. All data were transferred to the Northumbria Universities Multiple Access Computer and analysed using an SPSS-X package (SPSS-X Batch System, SPSS Inc., Chicago, Illinois, USA). Discrete variables were analysed using the chi-squared test with Yates' correction where appropriate. Continuous variables were analysed using the non-parametric Mann-Whitney $U$-test. 
Table I Patient details and reason for undergoing lumbar puncture

\begin{tabular}{lcc}
\hline & Supine $(\mathrm{n}=56)$ & Mobile $(\mathrm{n}=54)$ \\
\hline Sex (male:female) & $26: 30$ & $21: 33$ \\
Age (mean \pm S.D.) & $47(14)$ & $51(17)$ \\
Indication: & & \\
?MS & 23 & 21 \\
?MND & 6 & 10 \\
Neuropathy & 7 & 8 \\
Other & 20 & 15 \\
\hline
\end{tabular}

MS = multiple sclerosis; MND = motor neurone disease.

\section{Results}

Responses were obtained from $102(93 \%)$ patients, although not all of these replies were complete. The median interval between LP and completion of the questionnaire was 7 days. There was no difference between the mobile and supine groups in the frequency of PLPH (32\% compared with $31 \%$, respectively). There was also no difference between the two groups in the incidence of any headache after the LP (data not shown). Of those suffering PLPH, the mean delay between the LP and onset of headache was 17.5 hours in the supine group and 15.1 hours in the mobile group (a non-significant difference). The duration and severity of the headache was similar in both groups.

There was no significant difference between the grade of operator, gauge of needle used, opening pressure or the amount of blood in the CSF between the mobile and supine groups (Table II). Twenty-two $(69 \%)$ of the 32 patients with PLPH had red blood cells in the CSF compared with 37 $(54 \%)$ of the 69 patients without PLPH (a nonsignificant difference). There was no significant correlation between the opening pressure, and the presence or absence of PLPH.

\section{Discussion}

Whilst the definition of PLPH is an arbitrary one our definition is comparable to that used in other studies. The incidence of PLPH in our study is similar to that found in other reports, that is $31 \%$, and our patient population was representative of the population undergoing diagnostic $L P$ in a neurological unit. When explaining the procedure to our patients, we did not warn of the possibility of headache since this has been shown to increase the incidence of PLPH. ${ }^{6}$

We did not correlate the volume of CSF removed with the incidence of PLPH. It has been shown that there is no difference in the incidence of PLPH between removing up to $25 \mathrm{ml}$ of CSF and merely performing a dural puncture. ${ }^{7}$ This emphasizes that it is the continued leakage of CSF, at a rate faster than it is formed $(0.35 \mathrm{ml}$ per minute $)$ that is responsible for the generation of PLPH. ${ }^{8}$

We failed to demonstrate any difference in the incidence of PLPH between patients mobilized immediately after the procedure and those given 4 hours bed rest. This implies bed rest may be an unnecessary imposition on the patient as well as on the nursing staff.

Table II Comparison of grade of operator, opening pressure, gauge of needle used and CSF red blood cell count between the supine and mobile groups

\begin{tabular}{lcc}
\hline & Supine $(\mathrm{n}=56)$ & Mobile $(\mathrm{n}=54)$ \\
\hline $\begin{array}{l}\text { Grade of operator: } \\
\text { SHO: registrar/SR }\end{array}$ & $34: 22$ & $35: 19$ \\
$\begin{array}{l}\text { Opening pressure: } \\
\text { mm CSF }( \pm \text { S.D.) }\end{array}$ & $162(46)$ & $155(57)$ \\
$\begin{array}{l}\text { Gauge of needle: } \\
\quad 20 G: 21 G\end{array}$ & $53: 3$ & $49: 5$ \\
$\begin{array}{l}\text { CSF red cell count: } \\
\text { median/ } \mu \text { l }\end{array}$ & 2.5 & 2.0 \\
\hline
\end{tabular}

SHO $=$ senior house officer; $\mathrm{SR}=$ senior registrar. 


\section{References}

1. Hilton-Jones, D. What is a post-lumbar puncture headache and is it avoidable? In: Warlow, C.P. \& Garfield, T. (eds) Dilemmas in the Management of the Neurological Patient. Churchill Livingstone, Edinburgh, 1984, pp. 144-157.

2. Broker, R.J. Technique to avoid spinal tap headache. JAMA 1956, 168: 261-263.

3. Handler, C.E., Smith, F.R., Perkin, G.P. \& Rose, F.C. Posture and lumbar puncture headache: a controlled trial. $J R$ Soc $M e d$ 1982, 75: 404-407.

4. Hilton-Jones, D., Harrad, R.A., Gill, M.W. \& Warlow, C.P. Failure of postural manoeuvres to prevent lumbar puncture headache. J Neurol Neurosurg Psychiat 1982, 45: 743-746.
5. Carbaat, P.A.J. \& van Crevel, H. Lumbar puncture headache: controlled study of the preventative effect of 24 hours bed rest. Lancet 1981, ii: 1133-1135.

6. Gibb, W.R.G. \& Wen, P. Current practice of diagnostic lumbar puncture. $\mathrm{Br}$ Med J 1986, 289: 530.

7. Alpers, B.J. Lumbar puncture headache. Arch Neurol Psychiat 1925,$14 ; 806-812$.

8. Tourtellotte, W.W., Henderson, W.G., Tucker, R.P., Gilland, O., Walker, J.E. \& Kokman, E. A randomised, double-blind clinical trial comparing the 22 versus 26 gauge needle in the production of the post-lumbar puncture syndrome in normal individuals. Headache 1972, 12: 73-78. 